\title{
Hubungan antara Gangguan Pola Tidur dengan Keseimbangan Sistem Saraf Otonom pada Usia Dewasa Muda
}

\author{
Correlation between Sleep Pattern Disturbance and Stability of Autonomic Nervous System (ANS) \\ in Young Adult Age
}

\author{
Raden Mohamad Fachrur Rozy ${ }^{1}$, Nurvita Risdiana ${ }^{1 *}$ \\ ${ }_{1}$ Program Studi IImu Keperawatan, Fakultas Kedokteran dan IImu Kesehatan, Universitas Muhammadiyah Yogyakarta
}

DATA OF ARTICLE:

Received: 26 Juni 2018

Reviewed: 15 Juli 2018

Revised: 24 Agus 2018

Accepted: 3 Sep 2018

\section{*CORRESPONDENCE:} nurvita.risdiana@umy.ac.id

DOI:

$10.18196 / \mathrm{mm} .190120$

TYPE OF ARTICLE: Research
Abstrak: Gangguan pola tidur yang buruk berdampak negatif pada kesehatan yaitu ketidakseimbangan sistem saraf otonom. Ketidakseimbangan sistem saraf otonom akan berdampak pada rendahnya nilai Heart Rate Variability (HRV). Rendahnya nilai HRV akan berdampak pada mortalitas dan morbiditas. Heart Rate Variability terdiri atas time domain dan frekuensi domain. Standard Deviation of All N-N Intervals (SDNN) merupakan bagian dari HRV yang bisa digunakan untuk mengidentifikasi keseimbangan sistem saraf otonom. Usia dewasa muda rentan mengalami gangguan pola tidur, sehingga pada usia tersebut berisiko terjadi ketidakseimbangan SDNN. Penelitian ini bertujuan untuk mengetahui hubungan antara pola tidur dengan keseimbangan saraf otonom pada dewasa muda. Jenis penelitian ini merupakan penelitian kuantitatif non eksperimen dengan desain Cross sectional. Uji statistik menggunakan Spearman Rho. Sampel penelitian 31 orang dewasa muda dengan teknik purposive sampling. Data untuk gangguan pola tidur diambil menggunakan kuesioner, sedangkan pengukuran SDNN menggunakan Electrocardiogram (EKG). Didapatkan hasil $64,5 \%$ pola tidur pada dewasa muda dalam kategori baik, 35,5\% pola tidur mahasiswa dalam kategori cukup, 87,1\% mahasiswa memiliki SDNN yang sangat baik dan $9,7 \%$ mahasiswa memiliki SDNN tinggi. Hasil uji statistik menggunakan Spearmen Rho diperoleh nilai $p=0,11(p>0,05)$. Disimpulkan bahwa tidak ada hubungan antara gangguan pola tidur dengan kesimbangan saraf otonom.

Kata kunci: Gangguan Pola Tidur; Standard Deviation of All N-N Intervals; Sistem Saraf Otonom

Abstract: Sleep patterns disturbance makes the body unhealthy, as a result the autonomic nervous system imbalance. It decreases the value of Heart Rate Variability (HRV), then the risk of morbidity and mortality increases. HRV consist of time domain and frequency domain. Standard Deviation of All N-N Intervals (SDNN) is a part of HRV which controlled Autonomic Nervous System (ANS). Early adult has the risk for sleep disturbance because of their activity especially for nursing students. The, they have high risk for autonomic nervous system imbalance. This research purpose is to know the relationship between sleep pattern disturbances with ANS in young adults. This research was nonexperimental study with correlational design and cross sectional approach. This research samples are 31 male student which obtained chosen by purposive sampling techniques. Sleep pattern disturbances and HRV was measured by questionnaire and Electrocardiogram (ECG). The data was analyzed by Spearman Rho. There is no correlation between sleep pattern disturbance and SDNN with $p=0.11(p>0.05)$. 
Keywords: Autonomic Nervous System; Sleep Patterns Disturbances; Standard Deviation of All N-N Intervals

\section{PENDAHULUAN}

Tidur merupakan suatu aktivitas yang dilakukan setiap hari dan menjadi kebutuhan dasar manusia yang harus dipenuhi. Tidur merupakan keadaan aktif dan berulang yang terjadi pada setiap individu. ${ }^{1}$ Individu memerlukan tidur yang cukup untuk dapat berfungsi secara optimal. Pola tidur yang cukup pada orang dewasa adalah 7-8 jam per malam, tidak terkecuali pada orang yang sakit. ${ }^{2}$ Tidur sangat bermanfaat untuk kesehatan tubuh sehingga mereka yang mempunyai jam tidur terbatas dan sering terbangun mempunyai risiko empat kali lebih banyak mengalami serangan jantung. ${ }^{3} \mathrm{Hal}$ ini disebabkan karena jantung bekerja lebih berat jika individu kekurangan waktu tidurnya.

National Sleep Foundation (2011), ${ }^{4}$ melaporkan bahwa di Amerika pada tahun 2006 lebih dari 36\% dewasa muda usia 18-29 tahun mengalami kesulitan untuk bangun di pagi hari dan mengeluh mengantuk ketika beraktivitas sekurangnya 2 hari dalam seminggu atau lebih. Demikian juga yang terjadi pada mahasiswa keperawatan. Mahasiswa keperawatan termasuk dalam usia dewasa muda. Disamping itu pada tahun $2011,{ }^{4}$ juga dilakukan penelitian dan hasilnya meningkat dari 36\% pada tahun 2006 menjadi $51 \%$ yang mengalami gangguan tidur pada usia 18-29 tahun.

Pola tidur pada usia dewasa sangatlah berbeda dengan usia lainnya karena pada usia dewasa banyak mengalami perubahan aktivitas sehari-hari, seperti bekerja, ataupun kuliah. Keadaan tersebut dapat memicu terjadinya gangguan tidur. ${ }^{5}$ Gangguan pola tidur merupakan gangguan dalam jumlah, kualitas atau waktu tidur pada setiap individu. ${ }^{6}$ Gangguan tidur bukan hanya pada perubahan aktivitas sehari-hari, namun gangguan tidur juga dapat dipengaruhi beberapa faktor yaitu medis (penyakit) dan non-medis (gaya hidup). ${ }^{7}$ Begitu juga mahasiswa keperawatan yang sudah mempunyai perubahan aktifitas seperti kuliah ataupun aktifitas yang lain. Sehingga mahasiswa tersebut mempunyai risiko terjadinya gangguan pola tidur.

Aktivitas yang teratur, gaya hidup yang baik, pola tidur yang cukup merupakan faktor penting untuk dapat meningkatkan kesehatan jantung. Kualitas tidur yang buruk dapat menyebabkan kerugian kesehatan yang dapat menimbulkan penyakit jantung. ${ }^{8}$ Gangguan pola tidur dapat meningkatkan risiko penyakit jantung dan menyebabkan kematian jantung secara mendadak. Kondisi tersebut diyakini karena adanya ketidakseimbangan sistem saraf otonom dengan meningkatkan dominasi aktivitas simpatis daripada modulasi parasimpatis. ${ }^{8}$

Individu yang memiliki gangguan tidur yang buruk dikaitkan dengan penurunan saraf parasimpatis dan peningkatan saraf simpatis. ${ }^{9}$ Masalah tersebut disebabkan karena kulitas tidur yang buruk pada individu sebagai penyebab utama terjadinya penyakit jantung dan menurunkan Heart Rate Variability (HRV) serta dapat meningkatkan detak jantung. Demikian juga pendapat Rodriguez-colon et al. (2015), ${ }^{10}$ pola tidur yang tidak teratur dapat menurunkan HRV.

Heart Rate Variability adalah fenomena fisiologis yang mencerminkan indikator yang baik dari kontrol sistem saraf otonom yang berkaitan dengan kesehatan jantung. ${ }^{11}$ Sehingga pada kondisi individu yang memiliki gangguan tidur yang buruk mengalami penurunan aktifitas saraf simpatis, akibatnya terjadi ketidakseimbangan dari fungsi sistem saraf otonom. Ketidakseimbangan fungsi sistem saraf otonom dapat diukur dengan menggunakan HRV. Fungsi HRV adalah untuk menilai risiko kematian jantung secara mendadak. ${ }^{12}$ Oleh karena itu, nilai HRV yang tinggi merupakan tanda fungsi jantung sehat dan penurunan HRV adalah rentan terhadap kematian jantung secara mendadak. ${ }^{8}$ Pengukuran HRV terdiri dari dua pengukuran yaitu time domain dan frequncy domain. Frequency domain terdiri dari Low Frequency/LF (frekuensi rendah) dan High Frequency/HF (frekuensi tinggi). Low Frequency 0,04 - 0,15 Hz (Herz) dari perubahan R-R interval dan dimodulasi oleh aktivitas sistem saraf saraf simpatis, $\mathrm{HF}$ 0,15-0,40 $\mathrm{Hz}$ dari perubahan R-R interval dan dimodulasi oleh aktivitas sistem saraf parasimpatis. Time domain terdiri dari Standard Deviation of all N-N intervals (SDNN) dan Root Mean Square of Successive Differences (RMSSD). ${ }^{12}$ Standard Deviation of all $\mathrm{N}-\mathrm{N}$ intervals merupakan bagian dari HRV yang berperan dalam mengontrol sistem saraf otonom. Oleh karena itu nilai SDNN dapat digunakan untuk menilai adanya risiko kematian jantung mendadak melalui variasi dari $\mathrm{N}-\mathrm{N}$ interval. ${ }^{12}$

Tujuan penelitian ini adalah untuk mengetahui hubungan antara gangguan pola tidur dengan keseimbangan sistem saraf otonom pada dewasa muda.

\section{BAHAN DAN CARA}

Jenis penelitian ini merupakan penelitian kuantitatif non eksperimen dengan desain cross sectional yang bertujuan untuk mengetahui hubungan antara gangguan pola tidur dengan HRV pada dewasa muda. Responden pada penelitian ini adalah dewasa muda dengan usia antara 18-29 tahun yang dihitung berdasarkan rumus Arikunto (2010), ${ }^{13}$ 
dengan jumlah responden $20 \%$ dari total populasi yaitu 156 sehingga didapatkan responden sebanyak 31 responden. Setelah mendapatkan ijin etik dari Fakultas Kedokteran dan Ilmu Kesehatan Universitas Muhammadiyah Yogyakarta dengan nomor 131/EP-FKIK-UMY/IV/2016. Semua respoden menerima informasi dan menyatakan kesanggupannya melalui informed consent.

Data mengenai gangguan pola tidur diambil dengan menggunakan instrumen dari Jenkins et al. (1988), ${ }^{14}$ yang terdiri atas empat pertanyaan: "Pada sebulan terakhir seberapa sering anda mengalami sulit tidur, pada sebulan terakhir seberapa sering anda terbangun dimalam hari, pada sebulan terak hir seberapa sering anda terjaga dimalam hari pada saat anda ingin memulai untuk tidur, pada sebulan terakhir seberapa sering anda bangun tidur merasa lelah dan tidak bertenaga". Semua pertanyaan tersebut memiliki 6 pilihan jawaban sebagai berikut: a. Tidak pernah (nilai 0); b. 1-3 hari (nilai 1); c. 4-7 hari (nilai 2); d. 18-14 hari (nilai 3); e. 15-21 hari (nilai 4);f. 22-31 hari (nilai 5). Pada semua pertanyaan tentang pola tidur dapat dikategorikan baik < 50\% dengan nilai $0-9$, cukup $51-75 \%$ dengan nilai $10-15$, kurang 76 $100 \%$ dengan nilai $16-20$ pertanyaan. ${ }^{14}$

Data mengenai SDNN diambil dengan menggunakan EKG dan responden diukur selama 5 menit. Sebelum diukur, responden diberikan informasi untuk makan terakhir adalah 2 jam sebelum pengukuran. Selain itu untuk tidak mengkonsumsi teh, alkohol dan kafein 2 jam sebelum pengukuran. ${ }^{15}$ Disarankan kepada responden untuk buang air kecil atau besar sebelum pengukuran, ${ }^{16}$ tidak melakukan aktifitas berat 2 jam sebelum pengukuran. ${ }^{17}$ Pengukuran HRV merupakan pengukuran yang mudah dan bersifat noninvasive. Saat pengukuran, responden diminta untuk duduk atau tidur tenang bersandar dengan ketinggian kepala tidak lebih dari 15 derajat. Setelah responden siap, maka dilakukan perekaman EKG selama 5 menit. Setelah mendapatkan data rekaman EKG selama 5 menit, selanjutnya adalah melakukan analisis data. Data yang diambil adalah THB (Total Heart Beat) dan rerata $\mathrm{N}-\mathrm{N}$, selanjutnya dihitung berdasarkan rumus (I, II, III) selanjutnya dikategorikan sebagai berikut: buruk < $19 \mathrm{~ms}$; kurang 20-34 ms; baik 35-49; excellent > 50 ms).

$\mathrm{THB}=\mathrm{N}$

$\operatorname{MRR}=I=\frac{1}{N-1} \sum_{n=2}^{N} I(n)$

$\operatorname{SDNN}=\sqrt{\frac{1}{\mathrm{~N}}} \sum_{\mathrm{n}-2}^{\mathrm{N}}\left[(\mathrm{I}(\mathrm{n})-1]^{2}\right.$
Analisis data yang digunakan adalah univariat dan bivariat. Univariat digunakan untuk mengetahui gangguan pola tidur dan SDNN pada kelompok usia dewasa muda. Bivariat digunakan untuk mengetahui hubungan antara gangguan pola tidur dengan SDNN dengan menggunakan uji Spearman Rho.

\section{HASIL}

Responden pada penelitian ini merupakan mahasiswa keperawatan dengan kategori usia dewasa muda. Responden pada penelitian ini mempunyai rentang umur antara 21-23 tahun berjumlah 31 responden (100\%). Sebagian besar responden pada penelitian ini berjenis kelamin laki-laki berjumlah 29 responden (93,3\%) dan 2 responden lainnya berjenis kelamin perempuan (6,45\%). Karakteristik responden berdasarkan hubungan antara pola tidur dengan keseimbangan sistem saraf otonom pada usia muda dapat dilihat pada Tabel 1.

Gangguan pola tidur responden sebagian besar baik sebanyak 20 orang $(64,5 \%)$ dengan nilai rerata $86,25 \pm 6,04$ dan cukup sebanyak 11 orang $(35,5$ $\%$ ) dengan nilai rerata 73,63 $\pm 2,33$. Gangguang pola tidur responden dapat dilihat pada Tabel 2.

Berdasarkan Tabel 3. SDNN responden didominasi sangat tinggi sebanyak 27 orang $(87,1 \%)$ dengan nilai rerata $57,75 \pm 4,57$ sedangkan tinggi sebanyak 4 orang $(9,7 \%)$ dengan nilai rerata 48,33 $\pm 1,15$.

Berdasarkan hasil uji statistik dengan menggunakan uji Spearman Rho didapatkan hasil nilai $\mathrm{p}$ hubungan antara gangguan pola tidur dengan SDNN pada dewasa muda di Yogyakarta adalah $p=0,11$ ( $p$ $>0,05)$ sehingga dapat diambil kesimpulan bahwa tidak ada hubungan antara gangguan pola tidur dengan SDNN (Tabel 4).

Tabel 1. Karakteristik Responden Hubungan antara Pola Tidur dengan Keseimbangan Sistem Saraf Otonom pada Usia Dewasa Muda

\begin{tabular}{lcc}
\hline & Jumlah & Persentase (\%) \\
\hline Usia & & \\
$21-23$ tahun & 31 & $100 \%$ \\
Jenis Kelamin & & \\
Laki-laki & 29 & $93,54 \%$ \\
Perempuan & 2 & $6,45 \%$ \\
\hline
\end{tabular}

Tabel 2. Gangguan Pola Tidur Usia Dewasa Muda

\begin{tabular}{cccc}
\hline $\begin{array}{c}\text { Gangguan } \\
\text { Pola Tidur }\end{array}$ & Jumlah & Rerata \pm SD & $\begin{array}{c}\text { Presentase } \\
(\%)\end{array}$ \\
\hline Baik & 20 & $86,25 \pm 6,04$ & $64,5 \%$ \\
Cukup & 11 & $73,63 \pm 2,33$ & $35,5 \%$ \\
Kurang & 0 & 0 & 0 \\
\hline Jumlah & 31 & & $100 \%$ \\
\hline
\end{tabular}


Tabel 3. Standard Deviation of All N-N Intervals (SDNN) Usia Dewasa Muda

\begin{tabular}{cccc}
\hline SDNN & Jumlah & Rerata \pm SD & $\begin{array}{c}\text { Presentase } \\
(\%)\end{array}$ \\
\hline Sangat Tinggi & 27 & $57,75 \pm 4,57$ & $87,1 \%$ \\
Tinggi & 4 & $48,33 \pm 1,15$ & $9,7 \%$ \\
\hline Jumlah & 31 & & $100 \%$ \\
\hline
\end{tabular}

Tabel 4. Uji Statistik Hubungan antara Gangguan Pola Tidur dengan SDNN Dewasa Muda Rerata \pm SD

pada gangguan

Rerata \pm SD pola tidur

$\begin{gathered}\text { Hubungan } \\ \text { gangguan }\end{gathered}$
pola tidur $\quad 37,09 \pm 19,26 \quad 56,83 \pm 5,19 \quad 0,11$
dengan
SDNN

\section{DISKUSI}

Pola tidur adalah suatu aktivitas yang dilakukan setiap hari oleh setiap individu. Tidur merupakan proses fisiologis yang melibatkan sistem biologi dari molekuler sampai organ dan berperan dalam regulasi sistem saraf otonom khususnya dalam kontrol kardiovaskuler. ${ }^{18}$ Individu yang mengalami gangguan pola tidur dapat berdampak pada kesehatan salah satunya adalah kematian jantung secara mendadak. Hal ini sesuai dengan penjelasan Jackwoska et al. (2012), ${ }^{8}$ yang mengatakan bahwa kualitas tidur yang buruk dapat menyebabkan kerugian kesehatan yang dapat menimbulkan penyakit jantung, dan meningkatkan risiko penyakit kematian jantung secara mendadak. ${ }^{8}$ Kondisi tersebut diyakini adanya ketidakseimbangan ANS dan pelepasan sistem saraf simpatis yang dapat mengubah indeks HRV.

Perubahan indeks HRV dalam hal ini SDNN ini dapat mencerminkan adanya ketidakseimbangan sistem saraf otonom yang ditandai dengan hiperaktif sistem saraf simpatis dari pada sistem saraf parasimpatis. Hal tersebut dapat dilihat dengan pengukuran HRV yang rendah pada gangguan pola tidur. Individu yang memiliki gangguan pola tidur yang buruk dikaitkan dengan penurunan saraf parasimpatis dan peningkatan saraf simpatis. ${ }^{9}$

Berdasarkan hasil penelitian Tabel 2. mayoritas responden memiliki gangguan pola tidur baik sebanyak 20 orang (64,5\%). Gangguan pola tidur yang baik artinya sebagian responden telah melakukan gangguan pola tidur yang baik, namun tidak selalu dilakukan setiap hari. Dewasa muda yang merupakan masa transisi dari pubertas menuju dewasa, pada umumnya mengalami penurunan kepuasan tidur yang disebabkan karena faktor fisiologi dan psikososial. ${ }^{19}$ Nikotin, minuman yang mengandung kafein juga memberikan kontribusi dalam mempengaruhi kualitas tidur. ${ }^{19}$ Pada penelitian ini $64,5 \%$ mengalami gangguan pola tidur yang baik dan 35,5\% mengalami gangguan pola tidur yang cukup (Tabel 2). Hal tersebut sesuai pernyataan Stores (2009), ${ }^{19}$ yang menyatakan bahwa sebagian kecil responden $(35,5 \%)$ mulai mengalami penurunan kualitas tidur, namun tidak dengan responden lain (64,5\%) yang masih memiliki gangguan pola tidur yang baik. Responden dengan gangguan pola tidur yang baik $(64,5 \%)$ menurut Tabel 2 . sesuai dengan pernyataan Jenkins et al. (1998), ${ }^{14}$ yang mengatakan bahwa pola tidur yang baik bagi setiap individu 7-8 jam perhari dan tidak ada risiko kematian jantung mendadak.

Heart Rate Variability (HRV) adalah fenomena fisiologis yang mencerminkan indikator dari control ANS yang berkaitan dengan kesehatan jantung yang terbagi menjadi SDNN dan RMSSD. ${ }^{11}$ Standard Deviation of all N-N intervals (SDNN) mencerminkan kontrol dari ANS didalam tubuh yang berupa level SDNN. Standard Deviation of all N-N intervals yang tinggi menunjukkan kesimbangan ANS berupa keseimbangan antara saraf simpatis dan parasimpatis, namun pada SDNN yang rendah menunjukkan ketidakseimbangan antara saraf simpatis dan parasimpatis. Level SDNN yang rendah dapat menyebabkan risiko kematian jantung secara mendadak yang disebabkan karena ketidak seimbangan dari kontrol ANS. Pada penelitian ini sebagian besar level SDNN pada responden adalah sangat baik $(87,1 \%)$ dengan nilai rerata SDNN 57,75 $\pm 4,57$ (Tabel 3). Hasil penelitian tersebut artinya sistem otonom dapat mengatur fungsi dan kemampuan stres dengan sangat baik. Faktor lain yang mempengaruhi nilai SDNN yang sangat tinggi tersebut salah satunya disebabkan karena faktor usia. Menurut Yukishita et al. (2010), ${ }^{20}$ Aktifasi dari sistem saraf simpatis akan meningkat secara progresif dengan proses menua. Oleh karena itu semakin tua seseorang risiko untuk terjadinya ketidakseimbangan ANS meningkat. Responden pada penelitian ini dalam kategori dewasa muda menurut National Sleep Foundation (2011), ${ }^{4}$ yang berada dalam rentang usia 21-23 tahun (Tabel 1) sehingga risiko untuk terjadinya penurunan SDNN masih rendah. Hal tersebut sesuai dengan pendapat Zhang (2007), ${ }^{21}$ bahwa secara fisiologis nilai HRV pada lansia lebih rendah daripada orang muda.

Saat ini terjadi banyak perubahan pola aktifitas disebabkan karena perkembangan jaman, salah satunya adalah pola tidur. Pada jaman modern ini terjadi perubahan irama sirkadian karena tuntutan kebutuhan pada saat ini. Tuntutan pekerjaan atau- 
pun studi menyebabkan seseorang mengalami perubahan pola tidur sehingga terjadi gangguan pola tidur. Gangguan pola tidur dapat mempengaruhi keseimbangan sistem saraf otonom dengan menurunnya HRV. ${ }^{10}$

Berdasarkan hasil uji statistik Spearman Rho untuk mengetahui hubungan antara gangguan pola tidur dengan SDNN didapatkan hasil nilai $p=0,11(P>$ 0,05) (Tabel 4) yang berarti tidak ada hubungan antara gangguan pola tidur dengan SDNN. Pada penelitian ini didapatkan hasil bahwa sebagian besar responden memiliki gangguan tidur yang baik (Tabel 2) dan SDNN yang sangat tinggi (Tabel 3). Tidak adanya hubungan antara gangguan pola tidur dengan SDNN tersebut dapat terjadi disebabkan karena sebagian besar responden masih mempunyai gangguan pola tidur yang baik dan SDNN yang sangat baik. Menurut penelitian Rodriguez-colon et al. (2015), ${ }^{10}$ peningkatan $10 \%$ dari gangguan pola tidur akan menurunkan HRV. Pernyataan Rodriguezcolon et al. (2015), ${ }^{10}$ tersebut dapat disimpulkan bahwa gangguan pola tidur yang baik maka nilai HRV tidak menurun, sehingga sesuai dengan penelitian ini responden masih memiliki gangguan pola tidur yang baik dan nilai SDNN yang sangat baik. Demikian juga menurut Michels et al. (2013), ${ }^{22}$ pada pengukuran secara subjektif mengenai durasi tidur tidak berhubungan dengan HRV.

Namun, penelitian ini bertentangan dengan Rodriguez-colon et al. (2015), ${ }^{10}$ yang mendapatkan hasil bahwa peningkatan gangguan pola tidur berhubungan dengan rendahnya nilai HRV. Pola tidur yang bervariasi dapat menyebabkan rendahnya HRV sehingga menjadi prediktor ketidakseimbangan ANS dan risiko penyakit sistem kardiovaskuler dikemudian hari. $8,10,23,24$

\section{SIMPULAN}

Tidak ada hubungan antara gangguan pola tidur dengan keseimbanagn system saraf pada usia dewasa muda.

\section{DAFTAR PUSTAKA}

1. Siraj HH, Salam A, Roslan R, Hasan NA, Jin TH, Othman MN. Sleep Pattern and Academic Performance of Undergraduate Medical Students at Universiti Kebangsaan Malaysia. J Applied Pharmacentical Scie, 2014; 4 (12): 052-055.

2. National Institutes of Health. You're Guide to Healthy Sleep. Southern Medical Association. 2011.

3. Triyanta \& Haryati DS. Hubungan antara Kualitas Tidur dengan Denyut Jantung Dilihat dari Gambaran EKG pada Pasien Infark Miokard di
Ruang ICVCU RSUD Dr. Moewardi Surakarta. Jurnal KesMaDaSka, 2013; 4 (2): 123-131.

4. National Sleep Foundation. Annual Sleep in America Poll Exploring Connections with Communications Technology Use and Sleep. 2011. https://sleepfoundation.org/media-center/pressrelease/annual-sleep-america-poll-exploring-connectionscommunications-technology-use-

5. Gradisar M, Gardner G, Dohnt H. Recent Worldwide Sleep Patterns and Problems During Adolescence: A Review and Meta-analysis of Age, Region, and Sleep. Sleep Med, 2011; 12 (2): 110 118.

6. Mental Health Foundation. Sleep Matters. U.S Department of Health and Human Service. 2011.

7. Anne. Gaya Hidup Sehat. Bandung: Remaja Rosda Karya. 2010.

8. Jackowska M, Dockray S, Endrighi R, Hendrickx H, Steptoe A. Sleep Problems and Heart Rate Variability over the Working Day. J Sleep Res, 2012; 21 (4): 434-40.

9. Zhong X, Hilton HJ, Gates GJ. Increased Sympathetic and Decreased Parasympathetic Cardiovascular Modulation in Normal Humans with Acute Sleep Deprivation. J Appl Physiol, 2005; 98 (6): 2024-32.

10. Rodriguez-colon SM, He F, Bixler EO, FernandezMendoz J. Sleep Variability and Cardiac Autonomic Modulation in Adolescents - Penn State Child Cohort (PSCC) Study. Sleep Med, 2015; 16 (1): 67-72.

11. Corrales MM, Torres CB, Esquive GA, Salazar GM, Orellana NJ. Normal Values of Heart Rate Variability at Rest in a Young, Healthy and Active Mexican population. Health, 2012; 4 (7): 377-385.

12. Makivic B, Nikic DM, Willis SM. Heart Rate Variability (HRV) as a Tool for Diagnostic and Monitoring Performance in Sport and Physical Aktivities. J American Society of Exercise Physiol, 2013; 16 (3): 103- 131.

13. Arikunto. Prosedur Penelitian Suatu Pendekatan Praktik. Jakarta: Rineka Cipta. 2010.

14. Jenkins CD, Stanton BA, Niemcryk SJ, Rose SM. A Scale for the Estimation of Sleep Problems in Clinical Research. J Clin Epidemiol, 1988; 41(4): 313-21.

15. Braga LM, Prado GF, Umeda IIK, Kawauchi TS, Taboada AMF, Azevedo RS, et al. Reproducibility for Heart Rate Variability Analysis during 6-Min Walk Test in Patients with Heart Failure and Agreement between Devices. Plos One, 2016;11 (12).

16. Heathers JA. Everything Hertz: Methodological Issues in Short-Term Frequency-Domain HRV. Front Physiol, 2014; 5 (1): 177.

17. Wang HM \& Huang SC. SDNN/RMSSD as a 
Surrogate for LF/HF: A Revised Investigation. Modelling and Simulation in Engineering, 2012; 2012 (1): $1-8$.

18. Tobaldini E, Nobili L, Strada S, Casali KR, Braghiroli A, Montano N. Heart Rate Variability in Normal and Pathological Sleep. Front Physiol, 2013; 4 (1): 294.

19. Stores G. Aspects of Sleep Disorders in Children and Adolescents. Dialogues Clinical Neuroscience, 2009; 11 (1): 81-90.

20. Yukishita T, Lee K, Kobayashi A. Age and SexDependent Alterations in Heart Rate Variability: Profiling the Characteristics of Men and Women in Their 30s. Anti-Aging Medicine, 2010; 7 (8): 94 99.

21. Zhang J. Effect of Age and Sex on Heart Rate
Variability in Healthy Subjects. Journal Manipulative Physiology Therapy 2007; 30 (5): 374-9.

22. Michels N, Clays E, De Buyzere M, Huybrechts I, Marild S, Vanalest B, et al. Determinants and Reference Values of Short-Term Heart Rate Variability in Children. Eur J Applied Physiol, 2013; 113 (6): 1477-88.

23. Risdiana N. Comparison of Root Mean Square of Successive Differences (RMSSD) among Adolescent Smokers and Nonsmokers in Yogyakarta. Advanced Science Letters. 2017; 23 (12): 12660-12664.

24. Rozy RMF, Risdiana N. Hubungan antara Gangguan Pola Tidur dengan Heart Rate Variability. Karya Tulis Ilmiah: Universitas Muhammadiyah Yogyakarta. 2016. 